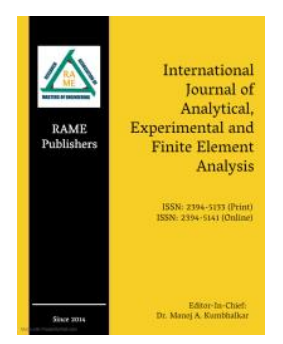

V. D. Karande

vijaykarande999@gmail.com

Sable Krushnakant

krushnakantsable@gmail.com

Deshmukh Digvijay

digvijaydeshmukh13@gmail.com

Dhumal Nikhil

nikhildhumal.nd4741@gmial.com

Dagadkhair Vishal dagadkhairv@gmail.com

${ }^{1}$ Assistant Professor and ${ }^{2}$ Student,

Department of Mechanical

Engineering, JSPM Narhe

Technical Campus, Pune, India

\title{
Fatigue Analysis of Welded Joint for T-Shape Plate
}

Abstract - A fracture mechanics technique has been used to estimate the fatigue strength of welded joints, taking into consideration the fatigue behaviour of small fractures, in this study. An important use of this approach is to calculate the rate of crack propagation as a function of the difference between a force and the material threshold for crack propagation. For the assessment of the fatigue behaviour of notched steel plates, analytical fatigue models have been created. Outcomes have been compared with results of foreign economic activity in order to forecast service life.

Keywords - welded joint, structure analysis, stress analysis, welded details.

\section{INTRODUCTION}

By heating materials to the proper temperature, with or without pressure, and with or without additional equipment, welds are used to connect materials together. For the construction of lasting connections, welding should be utilised [1].

It is used in the manufacturing of automotive bodywork, aircraft, RAM, rail cars, equipment, door and window frames, construction, building, boats, furniture, boilers, general maintenance, and ship building. When connecting metal or plastic, welding involves a process of melting, which differs from other techniques of connection such as soldering. It is not uncommon for the base metal to be melted with the addition of the base metal, creating a pool of molten material. Use the press in combination with heat, or by itself, for weld production. [1].

Research Paper - Peer Reviewed

Published online - 30 June 2021

(C) 2021 RAME Publishers

This is an open access article under the CC BY 4.0 International License https://creativecommons.org/licenses/by/4.0/

Cite this article - V. D. Karande, Sable Krushnakant, Deshmukh Digvijay, Dhumal Nikhil, Dagadkhir Vishal, "Fatigue Analysis of Welded Joint for T-Shape Plate", International Journal of Analytical, Experimental and Finite Element Analysis, RAME Publishers, vol. 8, issue 2, pp. 54-57, 2021.

https://doi.org/10.26706/ijaefea.2.8.20210609

\section{WELDING FORCES}

For the tool to remain in its place on or below the surface of the material, downward force is necessary. However, in many situations, frictionstir machines are placed vertically and hence need a shift of load during welding [3].

As the tool moves in the same direction as the head, its power has increased. Since the material and tool are both resisting each other, you may expect to notice a rise in temperature surrounding the tool [4].

Force acting perpendicularly to the direction of tool movement, lateral force is defined as being positive in relation to the opposite side of a joint's provision. torque necessary for tool whose size relies on strength loss and coefficient of friction (slide friction) (sticking friction) [5].

\section{A. Weld Joints}

It is possible to prepare a weld in many different manners from a geometrical standpoint.

However, there are five main types of weld joints (a variant of this last is the cruciform joint). Two pieces of material taper to a single centre point at one-half of their height in a double-V preparation joint; other variants are possible. 
It's also usual to have a single-U or double-U preparation joint. Instead of having straight edges, these joints have curved edges in the shape of $U$.

Depending on the thickness of the material and the welding method employed, multiple pieces can be welded together to form a lap junction. [6-7].

\section{B. Fatigue Overview}

- The fatigue damage is to the beginning and/or the extension of a crack under a varying load.

- The gradual accumulation of damage

- Almost all of the structural elements that are subjected to Fatigue failure occurs after repeated loadings, even though the stress is low.

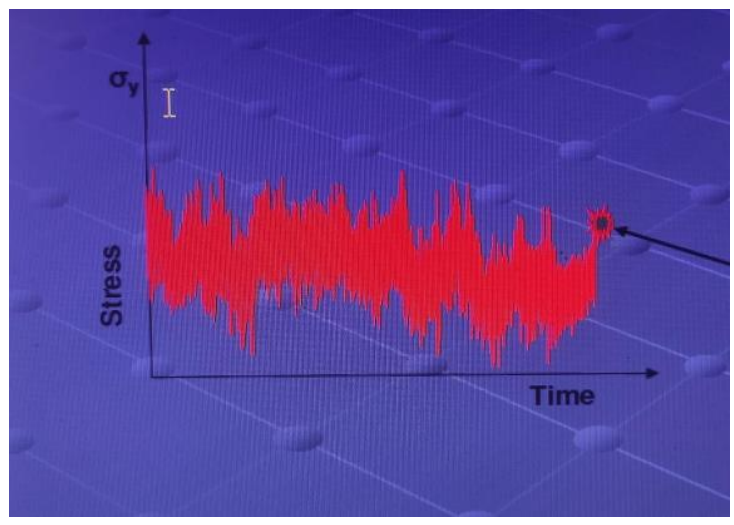

Figure 1. Repeated stress for high cycle fatigue [2]

Fatigue failure is typically viewed as 3-stage phenomena: stage 1: crack initiation stage 2: stable crack growth stage 3: fast fracture

Fatigue life $=$ crack initiation + crack growth No precise transition from crack initiation to crack growth. Up to $90 \%$ of fatigue life involves crack initiation.

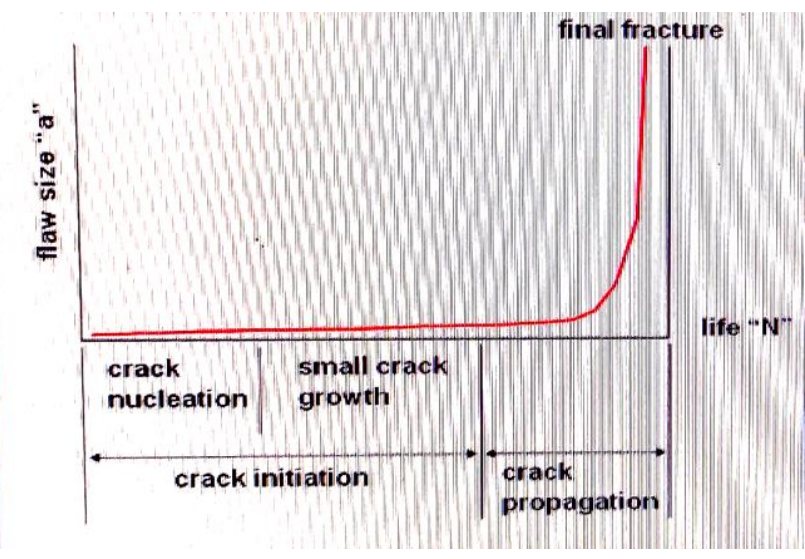

Figure 2. SN diagram
C. Weld Joint Characteristics

- Localized Discontinuities Exist

- Cracks already initiated

- Cyclic loading may result in crack growth

- A minimum acceptable flaw size is frequently specified; verified by NDT techniques (dyepenetrant, radiographic, etc.)

- Weld porosity (voids)

- slag or other inclusions

○ regions of incomplete fusion

- Impractical to model weld geometry with discontinuities in detail

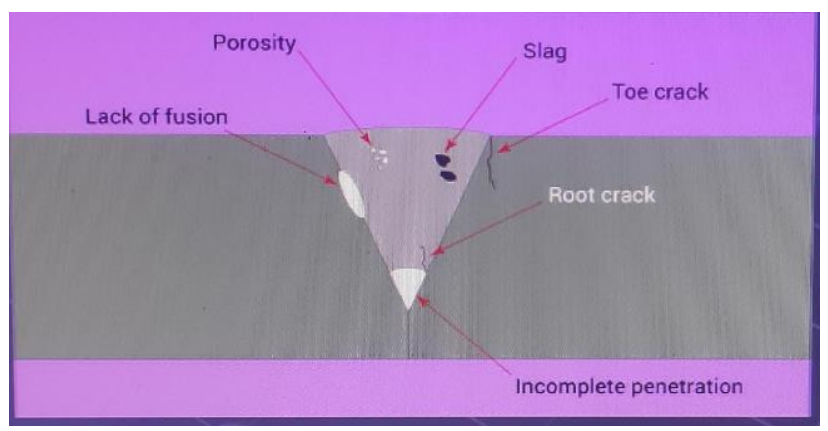

Figure 3. Localized Discontinuities

\section{FATIGUE FAILURE IN WELDS}

Handling features (lifting lugs, etc.) may become crack initiation sites Manufacturing tolerances may induce initial crackling Avoid joint eccentricity, welds at free edges Involve a welding engineer for proper joint design To improve fatigue life, increase base metal thickness and/or weld size (however, fracture life generally limited by joint fatigue (welded or bolted)Prudent fatigue penalty for thicker, stiffer joint!)Surface finish is a major factor influencing the material endurance limit. Others are loading type, size, temperature, and notch factor.

Solid works, mechanical design automation software, it is a functional, parametric modelling and design tool that takes advantage of the easy-to-use, Windows-TM graphical user interface. We will create a fully-connected, threedimensional solid models with or without them, with the help of an automatic, or custom links for the project as well. concentric, horizontal or vertical, etc. Numeric 
parameters can be associated with each other through the use of relations, which allow them to capture design intent Calculation-

- $\quad$ Plate $3 \mathrm{~mm}$ shear stress-

30.168 plate Force /Area

$32.007=$ Force $/ 60 \times 40 \times 5$

Shears Stress $=32.007 \mathrm{~N} / \mathrm{m}^{2}$

- $\quad$ Plate $4 \mathrm{~mm}$ Shear Stress

shear stress $=$ Force $/$ area $=30.9967 \mathrm{~N} / \mathrm{m}^{2}$

- $\quad$ Plate $5 \mathrm{~mm}=$ Force /area

Force $=362016 \mathrm{~N}$

Share stress $=$ force $/$ area $=30.168 \mathrm{~N} / \mathrm{m}^{2}$

Two plates of $60 \mathrm{~mm} \times 40 \mathrm{~mm} \times 5 \mathrm{~mm}$ are modeled and assembled by using weld bead.

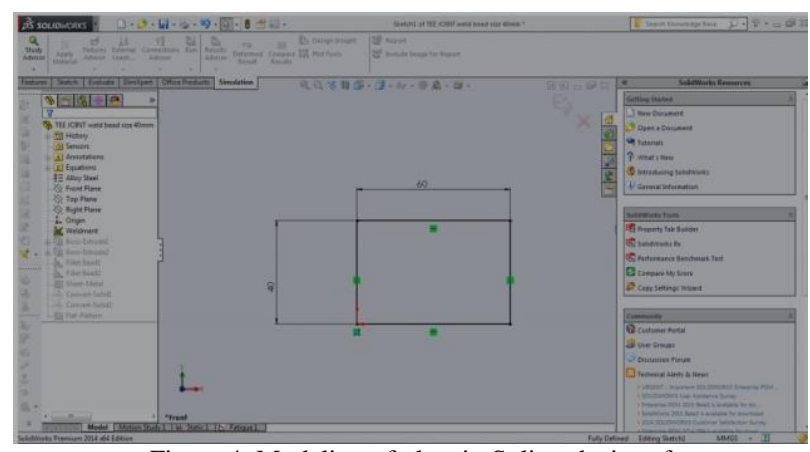

Figure 4. Modeling of plate in Soliworks interface

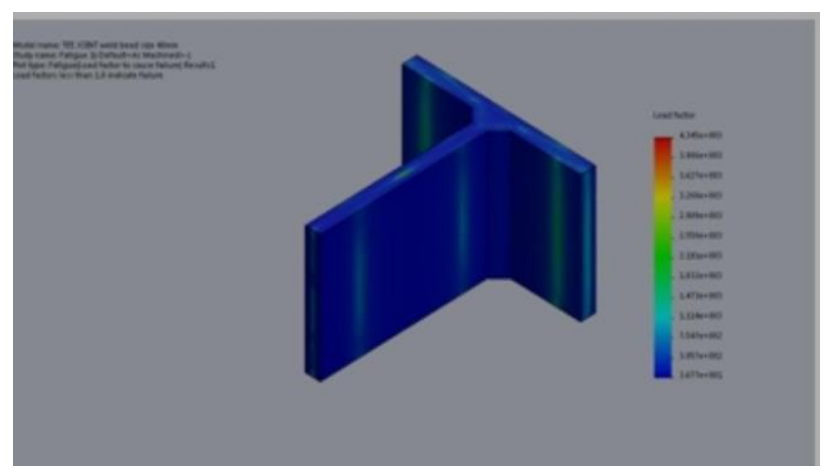

Figure 5. Load factor of weld joint

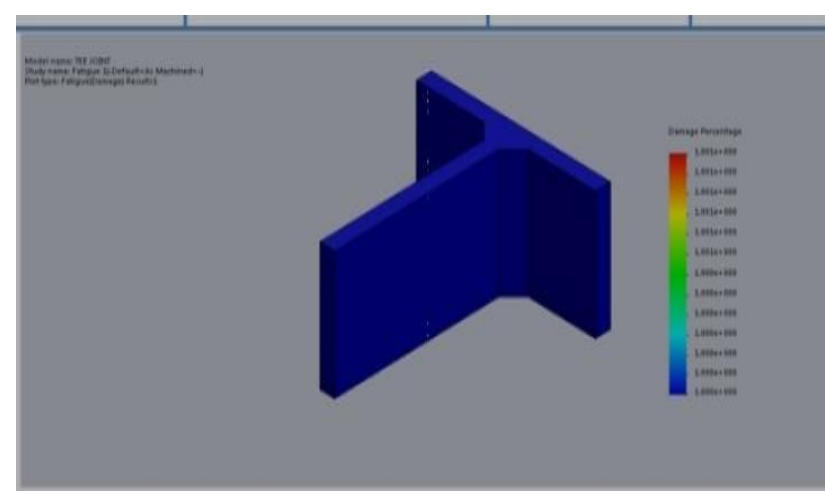

Figure 6. Life plot for weld joint

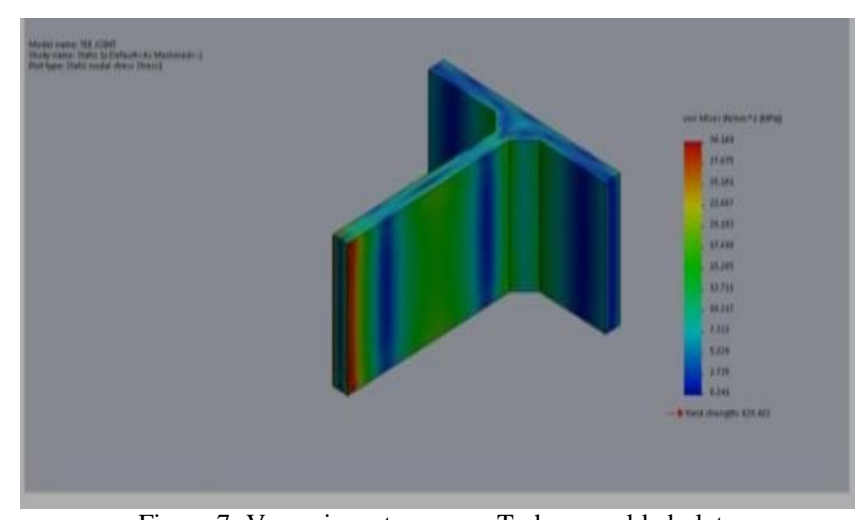

Figure 7. Von-mises stress over T-shape welded plate

TABLE I

FE ANALYSIS RESULTS FOR T-SHAPE WELDED PLATE

\begin{tabular}{|c|c|c|c|}
\hline Name & Type & Min & Max \\
\hline Result 1 & Load factor & 36.7711 & 4344.51 \\
\hline Result 2 & Life plot & 1 e+006cycle & $1 \mathrm{e}+006$ cycle \\
\hline Stress 1 & $\begin{array}{c}\text { VON: von } \\
\text { mises stress }\end{array}$ & $0.241231 \mathrm{~N} / \mathrm{mm}^{\wedge} 2$ & $30.1688 \mathrm{~N} / \mathrm{mm}^{\wedge} 2$ \\
\hline Strain 1 & $\begin{array}{c}\text { ESTRN: } \\
\text { equivalent } \\
\text { strain }\end{array}$ & $1.99567 \mathrm{e}-006$ & 0.00010627 \\
\hline Result 1 & Damage plot & 1 & 1 \\
\hline
\end{tabular}

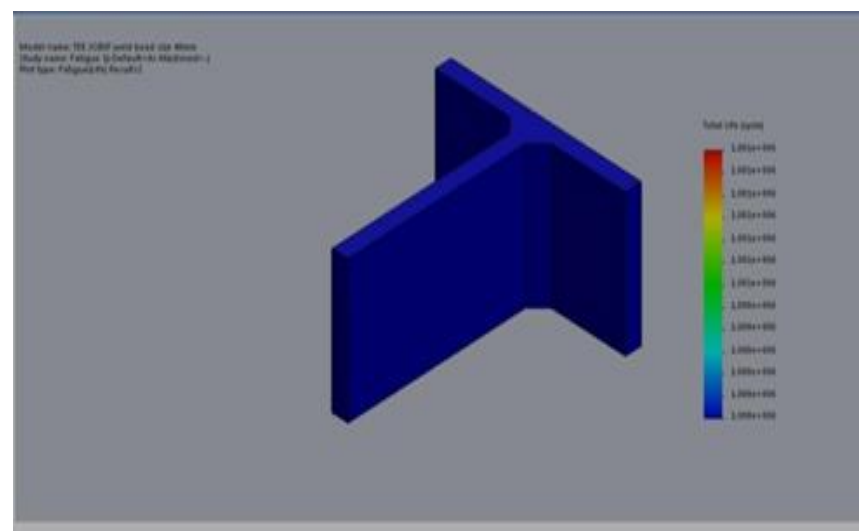

Figure 8. Fatigue analysis of welded joint of weld bead $5 \mathrm{~mm}$

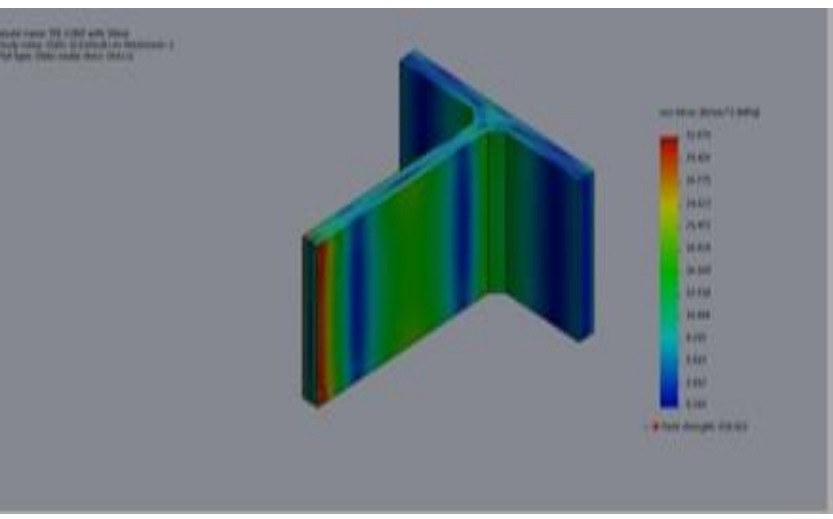

Figure 9. Structural analysis of weld plates of weld bead of $3 \mathrm{~mm}$ 


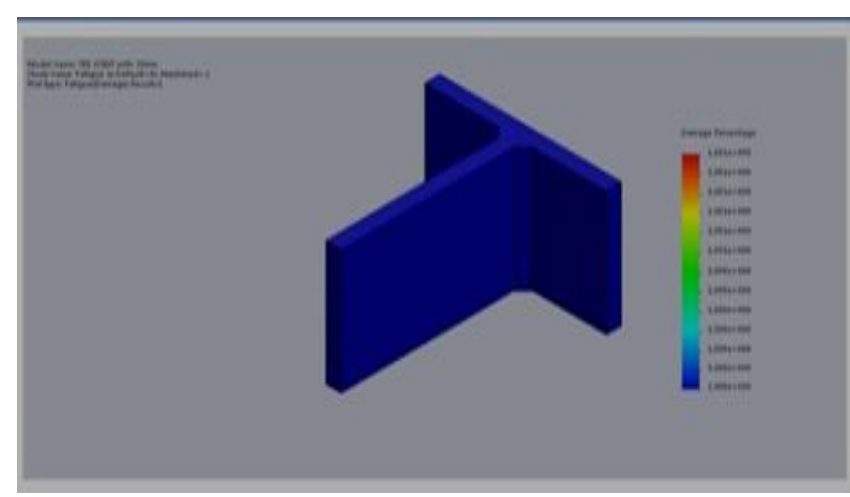

Figure 10. Fatigue Analysis of Welded Joint of Weld Bead 3mm

TABLE II

STRUCTURAL ANALYSIS RESULTS

\begin{tabular}{|c|c|c|c|}
\hline & $\begin{array}{c}\text { Weld bead } \\
3 \mathrm{~mm}\end{array}$ & $\begin{array}{c}\text { Weld bead } \\
4 \mathrm{~mm}\end{array}$ & $\begin{array}{c}\text { Weld bead } \\
5 \mathrm{~mm}\end{array}$ \\
\hline $\begin{array}{c}\text { Vonmisses stress } \\
(\mathrm{Mpa})\end{array}$ & 32.007 & 30.9968 & 30.168 \\
\hline $\begin{array}{c}\text { Resultant } \\
\text { displacement (mm) }\end{array}$ & 0.00971165 & 0.00921504 & 0.00873802 \\
\hline Equivalent strain & 0.000113874 & 0.000110669 & 0.00010627 \\
\hline
\end{tabular}

TABLE III

FATIGUE ANALYSIS RESULTS

\begin{tabular}{|c|c|c|c|}
\hline & $\begin{array}{c}\text { WELD BEAD } \\
3 \mathrm{MM}\end{array}$ & $\begin{array}{c}\text { WELD BEAD } \\
4 \mathrm{MM}\end{array}$ & $\begin{array}{c}\text { WELD BEAD } \\
5 \mathrm{MM}\end{array}$ \\
\hline LIFE PLOT & 1 & 1 & 1 \\
\hline DAMAGE PLOT & $1 \mathrm{E}-006 \mathrm{CYCLE}$ & 1E-006CYCLE & 1E-006CYCLE \\
\hline
\end{tabular}

\section{CONCLUSION}

The stress distribution in different welded Joints is investigated with a computer modeling technique.

The finite element analysis is used for the analysis of joints in the plane - stress condition, under static load.

Modeling is done in SOLIDWORKS and analysis is done in SOLIDWORKS Simulation. The $\mathrm{T}-$ joint Structural and fatigue analysis are done in solid works simulation. By observing the structural analysis as a result, all of the joints to be able to withstand the pressure exerted because of the stress that the values are lower than the yield strength of the steel. The combination of manufactured wood in a more stress than the other joints can be involved, so that if the load on the welded joint is higher, the wood, the combination of the crashes from the first one, then the other joint. The fatigue analysis is performed in order to analyze the fatigue of a material, service life thanks to application of a cyclic load. The observation of the results of the fatigue analysis, the use is more suitable for the welding of the seams, so that the service life of the weld joint is less than that of the other two joints

\section{REFERENCES}

[1] Mohammad Al-Emrani and Mustafa Aygül, "Fatigue-prone details in steel bridges", Buildings, Volume 2(4), pp. 456476. https://doi.org/10.3390/buildings2040456.

[2] Leap Australia, What is fatigue? Last access on 31 May 2021. Available at -

https://www.finiteelementanalysis.com.au/featured/what-isfatigue/

[3] Chien-Yuan Hou, "Fatigue analysis of welded joints with the aid of real three-dimensional weld toe geometry", International Journal of Fatigue, Volume 29, Issue 4, April 2007, Pages 772-785. https://doi.org/10.1016/j.ijfatigue.2006.06.007

[4] Jong-Hyeop Lee, Jun-Sik Kim, Seong-Uk Kang, Mikihito Hirohata \& Kyong-Ho Chang, "Fatigue life analysis of steel tube member with T-shaped welded joint by FEM", International Journal of Steel Structures, volume 17, pages833-841, 2017. https://doi.org/10.1007/s13296-017-6035-3

[5] Vincenzo Crupi, Eugenio Guglielmino, Antonino Risitano, David Taylor, "Different Methods for Fatigue Assessment of T Welded Joints Used in Ship Structures", Journal of Ship Research, Volume 51(2):150-159, May 2007. https://doi.org/10.5957/jsr.2007.51.2.150

[6] Biehn Baik, Kentaro Yamada and Toshiyuki Ishikawa, "Fatigue Strength of Fillet Welded Joint subjected to Plate Bending”, Steel Structures, Volume 8, 2008, 163-169.

[7] Jakob Klassen, Nils Friedrich, Wolfgang Fricke, Thomas Noel Nitschke-Pagel, Klaus Dilger, "Investigation on the fatigue strength of welded joints by full scale tests", Welding in the World, volume 61, pages 361-374, 2017. https://doi.org/10.1007/s40194-016-0407-8 